\title{
A Discriminant Function Analysis Approach to Country's Economy Status
}

\author{
Egbo M.N*and Bartholomew D.C \\ *Department of Statistics, Federal University of Technology, Owerri, Imo state, Nigeria \\ Email: egbomary4u@yahoo.com, bartholomewdesmond@gmail.com
}

\begin{abstract}
In this paper, discriminant function analysis was used to classify 68 randomly selected countries to their respective economy status (Weak or Strong) on World Bank website data. The following economic indicators were used as independent variables: Gross Domestic Product (GDP), Ln(Mortality_rate), $\quad \operatorname{Ln}($ Inflation_rate) and Access_to_electricicty. It showed that Ln(Mortality_rate) and Access_to_electricity contributed most to linearly discriminate within the group (economy status) for the two levels (weak or strong) while GDP contributed least with $93.6 \%$ sensitivity and $91.2 \%$ of cross-validated grouped cases correctly classified.
\end{abstract}

Keywords: Discriminant Function Analysis, randomly selected, economic indicators, sensitivity.

\section{Introduction}

Discriminant Analysis (also known as Discriminant Function Analysis, DFA) is a powerful descriptive and classificatory technique developed by R. A. Fisher in 1936[1] to (a) describe characteristics that are specific to distinct groups (called descriptive discriminant analysis); and (b) classify cases (that are individuals, subjects, participants) into pre-existing groups based on similarities between that case and the other cases belonging to the groups.

A set of discriminatory functions predicted the willingness of subscribers to drop their current service provider [2]. Discriminant analysis was employed to classify retail bank customers on the basis of users and non-users, and then they identified which variables contribute to the classification [3].

Discriminant analysis was used in [4] on the job applicants' results in Union Assurance Company Plc. A classification rule was obtained using the method of substitution. Comparison of the overall prediction performance of the two developed models for the prediction of bankruptcy in Slovak Republic was carried out in [5]. The first one was estimated via discriminant analysis, while the other was based on a logistic regression. The results of the study suggested that the model based on a logit function outperforms the classification accuracy of the discriminant model.

This study is based on only four economic indicators of 68 randomly selected countries of the world, including those with strong and weak economies. The average values of the indicator variables were used (2010 to 2014). That is, the average for the records from 2010 to 2014 for each country represents the value of an indicator variable for that country.

Economic strength is the resilience or the intrinsic strength of the economy, focusing on growth potential, diversification, competitiveness, wealth and scale, and is important in determining a country's resilience or shock-absorption capacity [6]. In other words, this tries to measure how strong the economy is in general. There are numerous economic indicators that are used to define the state of the economy or the economic strength of a country. Some of them include: Gross Domestic Product (GDP Annual \%), Inflation Rate (consumer prices Annual \%), Mortality Rate (Under 5 per 1000 live births), Access to electricity (\% of population), Rate of Unemployment (\% of Total Labor Force), Producer Price Index (PPI), Consumer Price Index (CCI), Manufacturing Trade Inventory and Sales, House Starts, Retail Number.

None of these economic indicators perfectly measures the economic strength. When one wants to know how well the economy is doing, the three most important indicators to look at are: the Gross Domestic Product (GDP), the inflation rate and the rate of unemployment [7]. But for the purpose of this research and having discovered that unemployment rate had no significant contribution to the model, we resorted to considering the following indicators that were significant: (a) Gross Domestic 
Product (b) Inflation rate (c) Mortality rate and (d) Access to electricity. The natural logs of Mortality_rate and Inflation_Rate were used with the GDP and Access_to_electricity data sets. This is the idea of dimension reduction which is one of the goals of discriminant function analysis.

\section{Discriminant Function Analysis (DFA)}

Discriminant Function Analysis is a classification method originally developed in 1936 by R.A Fisher. Consider two or more populations and a set of associated variables we may often want to locate a subset of the variables and an associated function of the subset that leads to maximum classification among the centroids of the groups. Classification analysis is a closely related multivariate technique to discriminant function analysis because it is concerned with the development of associated classificatory rules for assigning observations to one or more groups.

\subsection{Linear Discriminant Analysis (LDA)}

This is a type of Discriminant Function Analysis that finds linear functions of the associated variables that leads to maximum discrimination amongst the group centroids. It is used for dimension reduction. It is simple and mathematically robust in developing models whose accuracy is as good as more complex methods. Linear discriminant function may be used to obtain contrast in the sample mean vectors that leads to maximum separation of the sample group means when comparing the significance of two normal population means with a common variance-covariance matrix. One needs to verify that the null hypothesis of no difference in group means must be rejected for discriminant analysis to hold. A classification rule usually requires accurate understanding about the parametric structure of the groups.

\subsubsection{Assumptions of the Model}

The following assumptions amongst others apply to DFA:

The data from group $i$ has common variance-covariance matrix, where $i$ represents a discriminating group and $i$ runs from $1^{\text {st }}$ to $\mathrm{n}^{\text {th }}$ group.

The means of the independent variables are statistically significant.

Independence: The subjects are independently sampled.

Normality: The data are multivariate normally distributed.

The variables should not be highly correlated, this means that the correlation value should be not less than $(0.2$ or -0.2$)$ or more than $(0.9$ or -0.9$)$.

R.A Fisher developed the following Linear Discriminant (LD) equation:

$$
D=\phi_{1} x_{1}+\phi_{2} x_{2}+\ldots \ldots \ldots \ldots \ldots+\phi_{d} x_{d} \quad \text { LDA Equation }
$$

where $\phi_{1}, \phi_{2}, \ldots \ldots \ldots \phi_{d}$ are Model coefficients, $x_{1}, x_{2} \ldots \ldots \ldots \ldots . . x_{d}$ are measurements of independent variables (Gross Domestic Product, Inflation rate, Mortality rate and Access to electricity).

$$
S(\phi)=\frac{\phi^{\prime} \mu_{1}-\phi^{\prime} \mu_{2}}{\phi^{\prime} \sum \phi} \quad \text { Linear Score Function }
$$

where

$\mu_{1}=$ group 1 means (mean of the weak economy group)

$\mu_{2}=$ group 2 means (mean of the strong economy group)

$\Sigma=$ Pooled variance-covariance Matrix

$\phi^{\prime}=$ Transpose of $\phi$

Decision rule is based on the so-called Linear Score Function.

The problem is to estimate the linear coefficients that maximize the score which can be solved by:

$$
\phi=\Sigma^{-1}\left(\mu_{1}-\mu_{2}\right)
$$

Note: $\phi$ is a vector of linear model coefficients

where

$$
\sum=\frac{1}{n_{1}+n_{2}}\left(n_{1} \Sigma_{1}+n_{2} \Sigma_{2}\right)
$$


and $\Sigma_{1}=$ Variance-covariance matrix for group 1 (Weak economy),

$\Sigma_{2}=$ Variance-covariance matrix for group 2 (Strong economy).

\subsection{2a Classification Rule}

A new country is classified by projecting it into the maximally separating direction and classifying it as weak economy if

$$
\phi^{\prime}\left[X-\left(\frac{\mu_{1}+\mu_{2}}{2}\right)\right]>\log \frac{p(\text { weak })}{p(\text { strong })}
$$

where

$\phi=$ linear model coefficients

$X=$ Data vector

$p($ weak $), p($ strong $)=$ class probabilities

Note: if equation $\leq$ the R.H.S, we classify it as strong economy.

However, the class probabilities, means and variance-covariance matrix are estimated from the training data in which the population membership is known. A training data is a data in which the group memberships are known, for instance, we actually know which countries have weak or strong economy.

\subsection{2b Estimating Class Probabilities}

This represents the relative frequency with which the event (weak or strong) defined on a sample space (sampled c68 countries) would occur if the experiment (classification) was repeated a large number of times under identical conditions. The choices are as follow:

i. Equal class probabilities

$$
p=\frac{1}{n}
$$

If all the classes are equal in sample size.

ii. Arbitrary priors: Selected according to the investigator's beliefs regarding the relative class sizes.

$$
p_{1}+p_{2}+\ldots \ldots \ldots \ldots \ldots+p_{n}=1
$$

where $\mathrm{p}=\mathrm{i}^{\text {th }}$ class proportion in $\mathrm{n}$ number of classes e.g we have $\mathrm{n}=2$ (weak and strong economy) and $i$ runs from 1 to $n$.

iii. Estimated priors:

$$
p_{i}=\frac{n_{i}}{N}
$$

where

$n_{i}$ is the number of observations in each class.

$\mathrm{N}$ is the total sample size of the observations.

However, the population size, population mean and variance-covariance matrix are estimated from the training data in which the population membership is known.

\section{Result and Discussion}

In table 1, the data used for this work are secondary data and were sourced out online from World Bank

\begin{tabular}{|c|c|c|c|c|c|}
\hline COUNTRY & STATUS & GDP & $\begin{array}{l}\text { Access_to_- } \\
\text { Electricity }\end{array}$ & $\begin{array}{l}\text { Ln } \\
\text { (Mortality_rate) }\end{array}$ & $\begin{array}{l}\text { Ln } \\
\text { (Inflation_Rate) }\end{array}$ \\
\hline Afghanistan & 0 & 6.45 & 67.59 & 4.6 & 1.81 \\
\hline Albania & 0 & 2.12 & 100 & 2.74 & 0.92 \\
\hline Algeria & 0 & 3.29 & 99.91 & 3.27 & 1.55 \\
\hline Australia & 1 & 2.64 & 100 & 1.46 & 0.94 \\
\hline
\end{tabular}
website. The independent variables are GDP, Access_to_electricity, Ln(Mortality_rate) and Ln(Inflation_rate) while status coded in 0 s and 1 s is the group $(0=$ Weak, $1=$ Strong $)$.

Table 1. World Bank data 


\begin{tabular}{|c|c|c|c|c|c|}
\hline Benin & 0 & 4.69 & 36.18 & 4.67 & 0.85 \\
\hline Cambodia & 0 & 6.97 & 41.98 & 3.59 & 1.35 \\
\hline Gabon & 0 & 5.88 & 87.33 & 4.06 & 0.74 \\
\hline Gambia, The & 0 & 2.74 & 44.37 & 4.33 & 1.64 \\
\hline Georgia & 0 & 5.57 & 99.97 & 2.67 & 1.24 \\
\hline Germany & 1 & 2.06 & 100 & 1.39 & 0.42 \\
\hline Ghana & 0 & 8.51 & 69.49 & 4.24 & 2.41 \\
\hline Greece & 1 & -4.96 & 100 & 1.54 & 0.38 \\
\hline Guinea & 0 & 2.5 & 26.08 & 4.65 & 2.69 \\
\hline Guinea-Bissau & 0 & 3.07 & 11.62 & 4.66 & 0.63 \\
\hline Haiti & 0 & 1.99 & 37.28 & 4.62 & 1.82 \\
\hline Hong Kong SAR, China & 1 & 3.83 & 100 & 1.47 & 1.41 \\
\hline Hungary & 1 & 1.4 & 100 & 1.84 & 1.16 \\
\hline Iceland & 1 & 1.2 & 100 & 0.8 & 1.41 \\
\hline India & 0 & 7.25 & 76.14 & 4 & 2.26 \\
\hline Indonesia & 0 & 5.8 & 95.69 & 3.42 & 1.71 \\
\hline Iran, Islamic Rep. & 0 & 1.23 & 99.15 & 2.87 & 3.13 \\
\hline Iraq & 0 & 7.03 & 98.42 & 3.55 & 1.33 \\
\hline Ireland & 1 & 2.09 & 100 & 1.38 & -0.22 \\
\hline Israel & 1 & 4.1 & 100 & 1.46 & 0.68 \\
\hline Italy & 1 & -0.43 & 100 & 1.34 & 0.56 \\
\hline Jamaica & 0 & 0.17 & 94.61 & 2.84 & 2.19 \\
\hline Japan & 1 & 1.58 & 100 & 1.12 & -0.88 \\
\hline Jordan & 0 & 2.69 & 99.72 & 2.98 & 1.45 \\
\hline Kazakhstan & 0 & 5.94 & 99.86 & 2.9 & 1.89 \\
\hline Kenya & 0 & 6.06 & 27.36 & 4.03 & 2.08 \\
\hline Korea, Rep. & 1 & 3.74 & 100 & 1.35 & 0.85 \\
\hline Kuwait & 1 & 3.11 & 100 & 2.29 & 1.29 \\
\hline Lao PDR & 0 & 8.05 & 72.93 & 4.31 & 1.73 \\
\hline Latvia & 1 & 2.27 & 100 & 2.17 & 0.21 \\
\hline Lesotho & 0 & 4.7 & 23.26 & 4.56 & 1.61 \\
\hline Liberia & 0 & 6.34 & 6.95 & 4.39 & 2.08 \\
\hline Lithuania & 1 & 3.71 & 100 & 1.75 & 0.66 \\
\hline Luxembourg & 1 & 3.33 & 100 & 0.77 & 0.76 \\
\hline Macao SAR, China & 1 & 13.23 & 100 & 2.62 & 1.66 \\
\hline Macedonia, FYR & 0 & 2.36 & 100 & 2.04 & 0.81 \\
\hline Madagascar & 0 & 2.06 & 15.21 & 4.02 & 2 \\
\hline Malawi & 0 & 4.9 & 8.92 & 4.36 & 2.86 \\
\hline Malaysia & 0 & 5.69 & 99.73 & 2.04 & 0.86 \\
\hline Maldives & 0 & 5.81 & 98.93 & 2.39 & 1.98 \\
\hline Mali & 0 & 3.43 & 24.97 & 4.85 & 0.66 \\
\hline Mauritania & 0 & 5.39 & 34.93 & 4.53 & 1.59 \\
\hline Mauritius & 0 & 3.81 & 99.17 & 2.68 & 1.39 \\
\hline Mexico & 0 & 3.36 & 99.4 & 2.73 & 1.36 \\
\hline Moldova & 0 & 5.48 & 99.97 & 2.81 & 1.77 \\
\hline Montenegro & 0 & 1.66 & 100 & 1.76 & 0.64 \\
\hline Morocco & 0 & 3.83 & 89.21 & 3.43 & 0.1 \\
\hline Mozambique & 0 & 7.12 & 19.55 & 4.52 & 1.87 \\
\hline Namibia & 0 & 5.66 & 47.29 & 3.91 & 1.71 \\
\hline Nepal & 0 & 4.63 & 76.8 & 3.72 & 2.21 \\
\hline Netherlands & 1 & 0.65 & 100 & 1.43 & 0.65 \\
\hline New Zealand & 1 & 2.38 & 100 & 1.79 & 0.68 \\
\hline Niger & 0 & 6.96 & 13.84 & 4.71 & 0.11 \\
\hline Nigeria & 0 & 5.74 & 54.52 & 4.8 & 2.37 \\
\hline
\end{tabular}




\begin{tabular}{llllll}
\hline Rwanda & 0 & 7.25 & 13.66 & 3.97 & 1.4 \\
Uganda & 0 & 5.56 & 15.26 & 4.18 & 2.23 \\
Ukraine & 0 & 0.66 & 100 & 2.36 & 1.79 \\
United Kingdom & 1 & 1.94 & 100 & 1.57 & 1.07 \\
United States & 1 & 2.08 & 100 & 1.95 & 0.69 \\
Uruguay & 1 & 4.88 & 99.38 & 2.44 & 2.09 \\
Venezuela, RB & 0 & 1.93 & 98.95 & 2.77 & 3.57 \\
Vietnam & 0 & 5.86 & 99.18 & 3.16 & 2.25 \\
Zambia & 0 & 6.64 & 23.88 & 4.31 & 1.98 \\
Zimbabwe & 0 & 10.68 & 35.5 & 4.38 & 0.85 \\
\hline
\end{tabular}

Table 2. Group descriptive statistics

\begin{tabular}{llllll}
\hline & & & \multicolumn{3}{c}{ Valid N (list wise) } \\
Status of the nation's economy & Mean & Std. Deviation & Unweighted Weighted \\
\hline weak & Access_to_electricity & 63.5059 & 35.44922 & 47 & 47.000 \\
& GDP & 4.7983 & 2.25452 & 47 & 47.000 \\
& Ln(Mortality_rate) & 3.6670 & .87517 & 47 & 47.000 \\
& Ln(Inflation_Rate) & 1.6479 & .73045 & 47 & 47.000 \\
strong & Access_to_electricity & 99.9707 & .13437 & 21 & 21.000 \\
& GDP & 2.6105 & 3.17326 & 21 & 21.000 \\
& Ln(Mortality_rate) & 1.6157 & .48380 & 21 & 21.000 \\
& Ln(Inflation_Rate) & .7845 & .64337 & 21 & 21.000 \\
Total & Access_to_electricity & 74.7671 & 33.92399 & 68 & 68.000 \\
& GDP & 4.1226 & 2.74454 & 68 & 68.000 \\
& Ln(Mortality_rate) & 3.0335 & 1.22771 & 68 & 68.000 \\
& Ln(Inflation_Rate) & 1.3813 & .80709 & 68 & 68.000 \\
\hline
\end{tabular}

Table 2 above summarizes the independent variable data for the two levels of the population group. We can see that 47 countries used for this research have weak economy, while 21 have strong economy. On average, the weak economy countries had about 63.5 average accesses to electricity from 2010 to 2014 while the strong economy countries had almost $100 \%$ average access to electricity.

Table 3. Tests of equality of group means

\begin{tabular}{cccccc}
\hline & Wilks' Lambda & F & df1 & df2 & Sig. \\
\hline Access_to_electricity & .750 & 22.036 & 1 & 66 & .000 \\
GDP & .862 & 10.536 & 1 & 66 & .002 \\
LogMortality_rate & .395 & 100.992 & 1 & 66 & .000 \\
LogInflation_Rate & .752 & 21.760 & 1 & 66 & .000 \\
\hline
\end{tabular}

Table 3 above shows the test of equality of group means. The Wilks' Lambda test for equality of group means is significant since the p-values are less than 0.05 level of significance. Therefore, we are $95 \%$ confident that the group means differs significantly. 
Table 4. Pooled within-groups matrices

\begin{tabular}{cccccc}
\hline & & $\begin{array}{c}\text { Access_to_- } \\
\text { electricity }\end{array}$ & GDP & $\begin{array}{c}\text { Ln } \\
\text { (Mortality_rate) }\end{array}$ & $\begin{array}{c}\text { Ln } \\
\text { (Inflation_Rate) }\end{array}$ \\
\hline Correlation & Access_to_electricity & 1.000 & -.198 & -.770 & -.014 \\
& GDP & -.198 & 1.000 & .384 & .095 \\
& Ln(Mortality_rate) & -.770 & .384 & 1.000 & .116 \\
& Ln(Inflation_Rate) & -.014 & .095 & .116 & 1.000 \\
\hline
\end{tabular}

Table 4 shows the correlations between independent variables. Other variables do not have significant correlations except for Ln(Mortality_rate) and Access_to_electricity which have moderately negative correlation. This simply implies that the more people die, the number of people per family reduces which also reduces the load on the transformer, and thereby lesser people would enjoy higher access to electricity and vice versa.

We first perform the test of equality of population covariance matrix using Box's M test, which tests the null hypothesis of homogenous covariance matrices.

Table 5. Test of covariance matrix

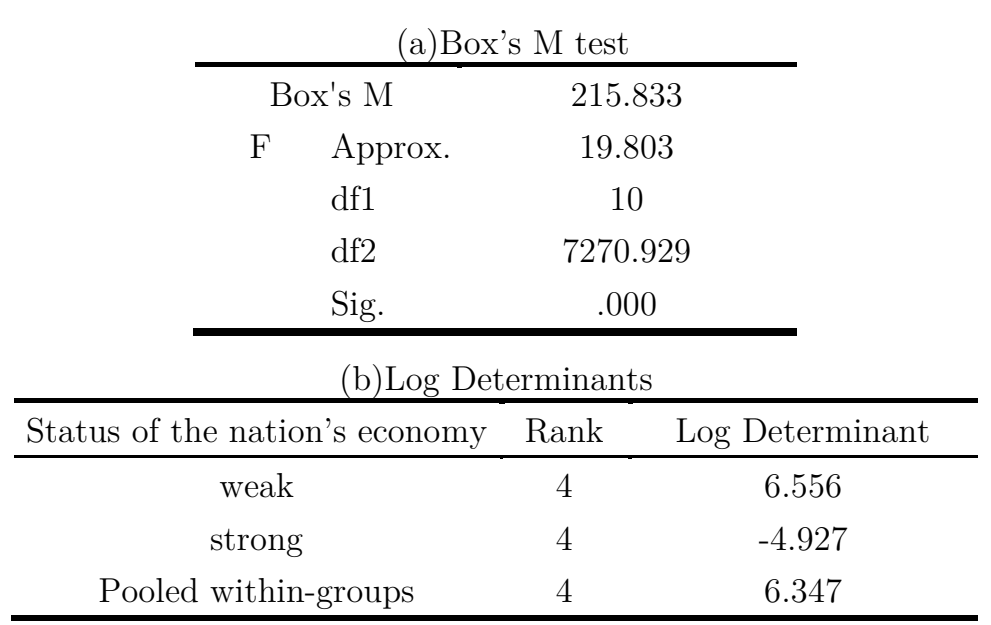

According to Table 5, Box's M test is significant, since the $p$-value is less than the level of significance $5 \%$ (that is $p$-value $=0.00<0.05$ ), therefore we do not accept the homogenous matrices hypothesis at $95 \%$ confidence. But the absolute values of $\log$ determinant are not significantly different and the sample size for each level of the dependent group is at least four times the number of independent variables. So we may go on with linear discriminant function. The rank value of 4 indicates that we are considering only 4 independent variables for the purpose of this research.

Normal P-P plot of LogInflation_Rate

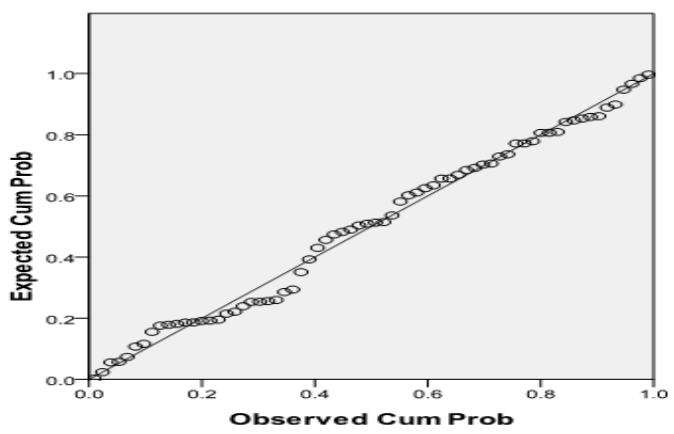

Normal P-P Plot of LogMortality_Rate

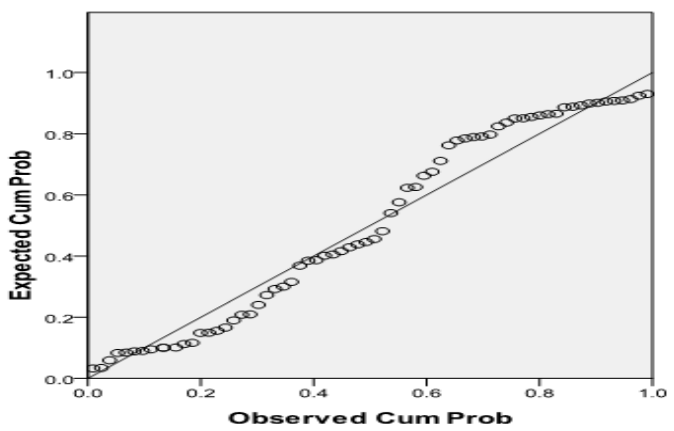



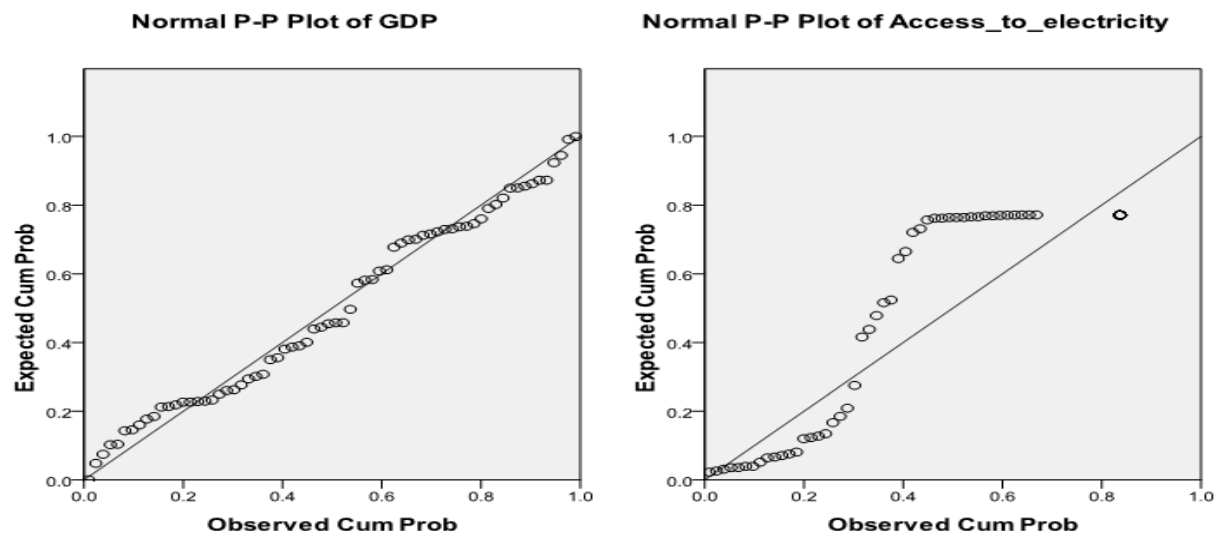

Figure 1. The plots of Observed cumulative Probabilities against the Expected Cumulative Normal Probabilities for the indicator variables do not show significant difference from the Normal variate. Therefore, we may assume that the variables follow the normal distribution.

Table 6. Eigenvalues and canonical correlation

\begin{tabular}{lcccc}
\hline Function & Eigenvalue & \% of Variance & Cumulative $\%$ & Canonical Correlation \\
\hline 1 & 2.045 & 100.0 & 100.0 & .820 \\
\hline
\end{tabular}

Table 6 above is the canonical correlation, which determines how much in percentage the DF explains the discrimination between groups. We can achieve this by increasing the canonical correlation to its squared value. Thus $r^{2}=(0.820)^{2}=0.674$ i.e. the function explained $67.4 \%$ of the discrimination between groups.

Table 7. Wilks' Lambda test

\begin{tabular}{ccccc}
\hline Test of Function(s) & Wilks' Lambda & Chi-square & df & Sig. \\
\hline 1 & .328 & 71.272 & 4 & .000 \\
\hline
\end{tabular}

Table 7 above shows that the discriminant function is statistically significant since p-value $=0.000<$ 0.05 , with Wilk's lambda being 0.328 which is closer to 0 than it is to 1 . This indicates that the two groups; "Weak" and "Strong" economy seem to differentiate quite well.

Table 8. Standardized canonical discriminant function coefficients

\begin{tabular}{cc}
\hline & Function \\
\cline { 2 - 2 } & 1 \\
\hline Access_to_electricity & .628 \\
GDP & -.149 \\
Ln(Mortality_rate) & 1.375 \\
Ln(Inflation_rate) & .265 \\
\hline
\end{tabular}

The standardized discriminant function coefficients in the table serve the same purpose as beta weights in multiple regressions (partial coefficient): they indicate the relative importance of the independent variables in predicting the dependent. They allow you to compare variables measured on different scales. Coefficients with large absolute values correspond to variables with greater discriminating ability. The absolute value of the standardized function coefficients shows that logMortality_rate, Access_to_Electricity and logInflation_rate, are the most important variables in 
discriminating economy status with $1.375,0.628$ and 0.265 values respectively. Notice also that GDP is the least important since it is the lowest with 0.149. Hence, Mortality_rate and Access_to_Electricity strongly discriminate economy status.

Table 9. The structure matrix

\begin{tabular}{cc}
\hline & Function \\
& 1 \\
\hline LogMortality_rate & .865 \\
Access_to_electricity & -.404 \\
LogInflation_Rate & .401 \\
GDP & .279 \\
\hline
\end{tabular}

The structure matrix table shows the correlations of each variable within each discriminant function. The correlations then serve like factor loadings in factor analysis, that is, by identifying the largest absolute correlations associated with each discriminant function, the researcher gains insight into how to name each function. No absolute value of the correlations should be less than 0.300 . Variables with high structure matrix value play a significant role in the DFA.

Table 10. The canonical discriminant function coefficients

\begin{tabular}{cc}
\hline & Function \\
& 1 \\
\hline Access_to_electricity & .021 \\
GDP & -.058 \\
LogMortality_rate & 1.768 \\
LogInflation_Rate & .376 \\
(Constant) & -7.229 \\
\hline
\end{tabular}

This table contains the unstandardized discriminant function coefficients. These would be used like unstandardized b (regression) coefficients in multiple regressions - that is, they are used to construct the actual prediction equation which can be used to classify new cases.

Discriminant function: our model

$D=-7.229+0.376 \ln ($ Inflation_rate $)+1.768 \ln ($ Mortality_rate $)-0.58 G D P+0.21$ Access_to_electricity

Table 11. The functions at group centroids

\begin{tabular}{cc}
\hline Status of the nation's economy & $\frac{\text { Function }}{1}$ \\
\hline weak & .942 \\
strong & -2.108 \\
\hline
\end{tabular}

Centroids are the mean discriminant scores for each group. This table is used to establish the cutting point for classifying cases. The computer does the classification automatically but for information purposes; if the two groups are of equal size, the best cutting point is half way (that is average of the functions), otherwise the weighted average of the centroids is used. 
Table 12. Classification function coefficients

\begin{tabular}{ccc}
\hline & \multicolumn{3}{c}{ status of the nation's economy } \\
& weak & strong \\
\hline Access_to_electricity & .487 & .422 \\
GDP & -.632 & -.455 \\
LogMortality_rate & 20.993 & 15.602 \\
LogInflation_Rate & 1.133 & -.012 \\
(Constant) & -53.725 & -34.263 \\
\hline
\end{tabular}

Two sets (one for each dependent group) of unstandardized linear discriminant coefficients are calculated, which can be used to classify cases. This is the classical method of classification, though now little used.

Table 13. Classification results

\begin{tabular}{|c|c|c|c|c|c|}
\hline & & \multirow{2}{*}{ Status of the nation's economy } & \multicolumn{3}{|c|}{ Predicted Group Membership } \\
\hline & & & weak & strong & 100 \\
\hline \multirow{4}{*}{ Original } & \multirow{2}{*}{ Count } & weak & 44 & 3 & 47 \\
\hline & & strong & 3 & 18 & 21 \\
\hline & \multirow{2}{*}{$\%$} & weak & 93.6 & 6.4 & 100.0 \\
\hline & & strong & 14.3 & 85.7 & 100.0 \\
\hline \multirow{4}{*}{ Cross-validated $^{\mathrm{a}}$} & \multirow{2}{*}{ Count } & weak & 44 & 3 & 47 \\
\hline & & strong & 3 & 18 & 21 \\
\hline & \multirow{2}{*}{$\%$} & weak & 93.6 & 6.4 & 100.0 \\
\hline & & strong & 14.3 & 85.7 & 100.0 \\
\hline
\end{tabular}

a. Cross validation is done only for those cases in the analysis. In cross validation, each case is classified by the functions derived from all cases other than that case.

b. $91.2 \%$ of original grouped cases correctly classified.

c. $91.2 \%$ of cross-validated grouped cases correctly classified.

Table 13 is used to assess how well the discriminant function works, and if it works equally well for each group of the dependent variable. Here it correctly classifies more than $90 \%$ of the cases, overall $91.2 \%$ of the cases are correctly classified. $93.6 \%$ indicates the sensitivity of the classification model. It can be observed that with the Cross Validated for the total sample of 68 cases, 44 (93.6\%) overall are correctly classified as weak economy. Note that this percentage is similar to the coefficient of determination, $\mathrm{R}^{2}$, in the regression model. Of the strong economy group $85.7 \%$ are correctly identified. This cross validation prediction of group membership provides a summary of how well the analysis would be at classifying new countries that have not been included in the original sample of countries. So far, we can deduce that the discriminant analysis validates the initial grouping of countries according to the categorical dependent variable status of economy before we started the analysis.

Table 14. Model prediction

\begin{tabular}{ccc}
\hline COUNTRY & STATUS & Predicted_Status \\
\hline Afghanistan & weak & weak \\
Albania & weak & weak \\
Algeria & weak & weak \\
Australia & strong & strong \\
\hline
\end{tabular}




\begin{tabular}{|c|c|c|}
\hline Benin & weak & weak \\
\hline Cambodia & weak & weak \\
\hline Gabon & weak & weak \\
\hline Gambia, The & weak & weak \\
\hline Georgia & weak & weak \\
\hline Germany & strong & strong \\
\hline Ghana & weak & weak \\
\hline Greece & strong & strong \\
\hline Guinea & weak & weak \\
\hline Guinea-Bissau & weak & weak \\
\hline Haiti & weak & weak \\
\hline Hong Kong SAR, China & strong & strong \\
\hline Hungary & strong & strong \\
\hline Iceland & strong & strong \\
\hline India & weak & weak \\
\hline Indonesia & weak & weak \\
\hline Iran, Islamic Rep. & weak & weak \\
\hline Iraq & weak & weak \\
\hline Ireland & strong & strong \\
\hline Israel & strong & strong \\
\hline Italy & strong & strong \\
\hline Jamaica & weak & weak \\
\hline Japan & strong & strong \\
\hline Jordan & weak & weak \\
\hline Kazakhstan & weak & weak \\
\hline Kenya & weak & weak \\
\hline Korea, Rep. & strong & strong \\
\hline Kuwait & strong & weak \\
\hline Lao PDR & weak & weak \\
\hline Latvia & strong & strong \\
\hline Lesotho & weak & weak \\
\hline Liberia & weak & weak \\
\hline Lithuania & strong & strong \\
\hline Luxembourg & strong & strong \\
\hline Macao SAR, China & strong & weak \\
\hline Macedonia, FYR & weak & strong \\
\hline Madagascar & weak & weak \\
\hline Malawi & weak & weak \\
\hline Malaysia & weak & strong \\
\hline Maldives & weak & weak \\
\hline Mali & weak & weak \\
\hline Mauritania & weak & weak \\
\hline Mauritius & weak & weak \\
\hline Mexico & weak & weak \\
\hline Moldova & weak & weak \\
\hline Montenegro & weak & strong \\
\hline Morocco & weak & weak \\
\hline Mozambique & weak & weak \\
\hline Namibia & weak & weak \\
\hline Nepal & weak & weak \\
\hline Netherlands & strong & strong \\
\hline New Zealand & strong & strong \\
\hline
\end{tabular}




\begin{tabular}{ccc}
\hline Niger & weak & weak \\
Nigeria & weak & weak \\
Rwanda & weak & weak \\
Uganda & weak & weak \\
Ukraine & weak & weak \\
United Kingdom & strong & strong \\
United States & strong & strong \\
Uruguay & strong & weak \\
Venezuela, RB & weak & weak \\
Vietnam & weak & weak \\
Zambia & weak & weak \\
Zimbabwe & weak & weak \\
\hline
\end{tabular}

\section{Statistical Software Used}

All calculations and analysis for DFA in this work were done with SPSS version 17.

\section{Conclusion}

So far, we have investigated the possibility of applying DFA to Economy status selection on the different countries of the world. The results of the analysis show that the four economic indicators applied with the DF model are significant in selecting economy status. Thus the main aim of this paper was to develop a discriminant function model that can be used to predict the group membership of a new country based on the values of her GDP, Mortality_rate, Inflatio-rate and Access_to_electricity, when a potential researcher is selecting status of some new selected countries. Cross validation prediction accuracy of $91.2 \%$ clearly indicates that the model can be reliably generalized to countries of unknown group membership. Mortality_rate and Acces_to_electricity contributed more in this research, followed by inflation_rate and finally GDP.

\subsection{Recommendation}

The following recommendation is made:

1. The Researchers need to investigate amongst all the laid out assumptions of DFA to verify the possibility of going on with the analysis otherwise consider Logistics Regression which is more robust in handling failed assumptions.

2. Researchers should focus on the assumption of No outlier and Difference in group means, as these two assumptions are very important in deciding the quality of the DF model. Only variables whose values are less than 0.3 in the structure matrix values should not be allowed to enter the model.

3. We recommend the use of economic indicators and Discriminant function analysis in selecting group membership of economy status.

\section{References}

1. Fisher, R. A. "The Use of Multiple Measurements annals of Eugenics". 1936, 7:179-188.

2. Oghojafor, B., Mesike, G., Bakarae, R., Omoera, C., and Adeleke, I. "Discriminant Analysis of Factors Affecting Telecoms Customer Churn," International Journal of Busine Administration, 2012, 3(2).

3. Okeke, T.C. \& Amobi, D.C. "A Discriminant Analysis of Electronic Banking in Nigeria," Journal of Emerging Trends in Economics 83 Management Science, (JETEMS), 2014, 5(2):194-200.

4. Chijioke, L.C. "A Discriminant Analysis of Applicant's Results in Union Assurance Company Plc," 2015, BSc Thesis, department of Statistics, University of Nigeria, Nsukka.

5. Mihalovic, M. "Performance Comparison of Multiple Discriminant Analysis and Logit Models in Bankruptcy Prediction," Economics and Sociology, 2016, 9(4):101-118. 
6. Cedric, C. "What is economic strength and how to measure it," Center of America Progress, 2014

7. Jim, G. "The Big Three Indicator. Discover Options, Trusted Education, Proven Results," 2016.

8. https://onlinecourses.science.psu.edu/stat505/node/91

9. https://onlinecourses.science.psu.edu/stat505/node/94

10. https://onlinecourses.science.psu.edu/stat505/node/97

11. Inflation Rate: Indicator of Sustainable Development Report, 2007. 